IFAS Extension

\title{
Making Good Decisions: Media and the Physical Health of Young Children $^{1}$
}

Stephanie C. Toelle and David C. Diehl ${ }^{2}$

Many parents are concerned that exposure to television and computers is affecting their children's health, particularly weight gain. This is especially true given the dramatic rise in overweight children over the last few decades.

The percentage of overweight preschoolers has more than doubled since the 1970 s. ${ }^{1}$ In a $2003-$

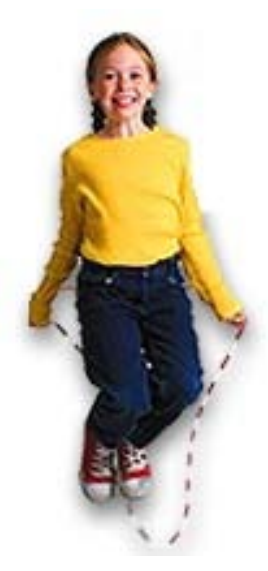

2004 study, $26 \%$ of children this age were overweight or at risk of becoming overweight. $^{2}$ The Centers for Disease Control and Prevention (CDC) classifies children as "overweight" if their body mass index (BMI) is above the $95^{\text {th }}$ percentile, and "at risk of being overweight" if they are between the $85^{\text {th }}$ and $95^{\text {th }}$ percentiles. $^{3}$

Figure 1: Support an active lifestyle for your children. Source: Public Domain Photo Retrieved from:

http://static.squidoo.com/resize/squidoo_images/1/draft_lens2077770module10574409photo_1216961070jumpin g_rope.jpg

An overweight child is four times more likely than a normal weight child to become an overweight adult. ${ }^{4}$ The trend of children becoming overweight is a serious health concern, as children who are overweight are at greater risk for health problems such as asthma, respiratory ailments, sleep apnea, type 2 diabetes, high blood pressure, orthopedic problems, and depression. ${ }^{5}$

Given the central role of media in American life and its possible role in childhood weight problems, parents should be aware of how television and computers can impact the health and weight status of young children.

To foster the healthy physical development of their children, some key questions for parents to consider include the following, which are addressed in this paper:

- Does the amount of time that children spend watching television and using computers contribute to children being overweight?

- Does watching television displace other physical activities in which children might engage?

- How does the television content that children watch, particularly advertising, affect their eating behaviors and weight status?

- Do children tend to eat unhealthy foods while they are watching television or using the computer?

- How can parents help maintain healthy weight in young children?

1. This publication is FCS2293, one of a series of the Department of Family, Youth and Community Sciences, Florida Cooperative Extension Service, Institute of Food and Agricultural Sciences, University of Florida. Publication: December 2008. Please visit the EDIS Web site at http://edis.ifas.ufl.edu

2. Stephanie C. Toelle, extension agent IV, Duval County Extension, Jacksonville, FL. David C. Diehl, Ph.D., assistant professor, Department of Family, Youth and Community Sciences, Cooperative Extension Service, Institute of Food and Agricultural Sciences, University of Florida, Gainesville, 32611. 
Connection between Screen Time and Children's Weight

Does the amount of time that children spend watching television and using computers contribute to children being overweight? Research points to media exposure as a key factor among the unhealthy habits that contribute to overweight. ${ }^{6}$ Young children under six years of age average two hours and 24 minutes of daily exposure to media content. ${ }^{7}$ In the case of young children, media typically involves the television, though it could include videos/DVDs, audio, games, and computers.

Watching more than two hours a day of television and/or videos/DVDs is associated with being overweight or at risk of becoming overweight, ${ }^{8}$ which supports the American Academy of Pediatrics (AAP) guideline of no more than two hours per day of screen time for children over two years (and no screen time for younger children).

Reducing television use can have a positive impact on children's weight. ${ }^{9}$ Unfortunately, almost $36 \%$ of preschool children exceed the AAP guideline. ${ }^{10}$ Further, high video game usage,

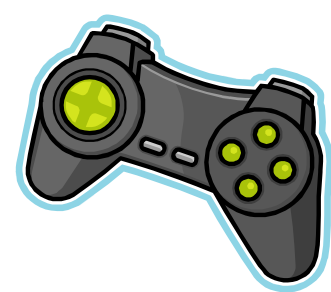
which is more common in higher economic status households, is related to overweight. ${ }^{11}$ Computer use is also related to higher levels of body fat in children. ${ }^{12}$ In sum, the

answer is yes - children who watch more television, play more video games, and spend more time on the computer are more likely to be overweight.

This leads to the key question: what is it about higher screen time that contributes to children being overweight?

\section{Connection between Screen Time and Children's Physical Activity}

"If it weren't for the fact that the TV set and the refrigerator are so far apart, some of us wouldn't get any exercise at all."

$$
\text { Joey Adams }
$$

Does watching television and using computers displace other physical activities in which children might engage that would contribute to good health? It is logical to think that children who watch more television and spend more time on the computer are getting less physical exercise, contributing to them being overweight. However, research is finding evidence that TV time does not cause less physical activity. That is, children who watch more television do not necessarily get less exercise than children who watch less television.

Reducing TV time does not mean that the kids will go outside and play. While less physical activity definitely contributes to children being more overweight, children who watch more TV are not necessarily less physically active than other children. ${ }^{13}$

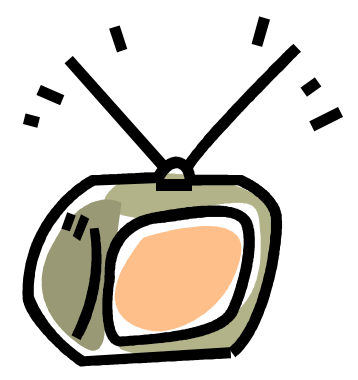
However, the combined effect of not getting adequate active play and spending over two hours a day watching a screen does increase the risk for being overweight. ${ }^{14}$

But what if children spend the same amount of time doing other sedentary activities, such as reading or crafts; would it have the same impact as watching TV? The answer is no. Research finds that the amount of energy used for watching $\mathrm{TV}$ is as low as, or lower than other sedentary activities. ${ }^{15}$

Also, TV has the strong influence of advertisements for unhealthy foods that other sedentary activities do not have. In addition, children are more likely to consume extra calories while watching TV, which is not true of most other hobbies such as reading or crafts. ${ }^{16}$ In fact, children who read more tend to eat a healthier diet and get more physical activity than children who read less. ${ }^{17}$

\section{Connection between Television Advertising and Children's Health}

How does the television content that children watch, particularly advertising, affect their eating behaviors and health? We just discovered that 
time in front of the TV does not necessarily displace physical activity, suggesting that the advertising and marketing of unhealthy foods to children may be a larger contributor to the weight gain crisis. ${ }^{18}$ A typical child sees about 40,000 advertisements per year on TV, consisting mostly of candy, cereal, soft drinks, and fast foods.

During 271/2 hours of Saturday morning programming in May 2005, just over 4 hours were devoted to advertisements, of which $49 \%$ of the advertisements were for food; ninety-one percent of these were for foods or beverages high in fat, sodium, or added sugars, or low in nutrients. Despite this nutritional breakdown, $42 \%$ of the food advertisements contained a health or nutrition message and $100 \%$ had an implicit physical activity message, which can be misleading at any age! ${ }^{19}$

Also, note that food manufacturers devote approximately $75 \%$ of their advertising budgets to television. ${ }^{20}$ Children often develop a preference for these advertised products and make purchase requests, ${ }^{21}$ creating conflicts when their parents deny these purchases. ${ }^{22}$ Advertisements are not restricted to TV, as they also appear on Web sites. The barrage of advertising of unhealthy snack foods to children makes it challenging for them to request healthy foods or even choose not to snack during a commercial break. It appears that advertising to children is a major reason for their weight gain.

\section{What Children Eat While Watching TV and Playing on the Computer}

Do children tend to eat foods of minimal nutritional value while they are watching television or using the computer? Research does support the idea that children eat less healthy food while watching television or using the computer. One of the ways families contribute to excessive viewing time is by allowing children to eat in front of the TV. Parents play a critical role in establishing young children's behaviors, habits, and attitudes about eating and use of media through modeling and determining their physical and social environments.
Approximately one-third of families with children under six years of age eat dinner with the TV on. Families who eat while watching TV tend to eat fewer healthy foods, particularly fruits and vegetables, and more foods of minimal nutritional value, such as chips, candy, and soft drinks. Further, this study concludes that "having dinner as a family does not overcome the adverse effects of having the television on during mealtime" ${ }^{23}$ On the other hand, eating as a family with the TV off is associated with more fruits and vegetables, fewer fried foods and soft drinks, less fat, and more micronutrients. ${ }^{24}$

In general, high TV/video and computer use is associated with consuming an unhealthy diet. In particular, high TV/video use is associated with consuming more soft drinks, fried foods, and snacks per day, and consuming fewer fruits and vegetables. There are gender differences with the computer. Girls who use the computer more eat more fruits and vegetables; boys do not.

However, computer use is also associated with more daily servings of soft drinks and snacks for boys, and soft drinks, fried food, and snacks for girls. ${ }^{25}$

Another study found that when presented with the opportunity to eat in front of a television, children

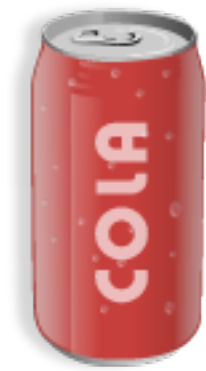
who watch a lot of television are more likely to eat more food compared to children who do not watch as much television. ${ }^{26}$ Children who eat while watching television are more likely to eat unhealthy foods and eat higher quantities of food, with mixed results regarding the computer. [See EDIS FCS2286 \& FCS8871 for more on the importance of family meal time.]

Overall, watching television, playing video games, and using the computer beyond AAP guidelines is associated with excessive weight gain and poor nutrition, so parents need to be conscious of the media habits and eating habits they are encouraging. 


\section{What Parents Can Do $^{27}$}

How can parents help maintain healthy weight in young children? Prevention is key. Research suggests that the community environment, restrictions on media use, increased physical activity, and a healthful diet are ways to avoid overweight.

- Support or protect your community environment. Provide opportunities for children and families to enjoy activity outdoors, through footpaths and trails, bicycle paths, and parks and recreation centers. Promote healthier choices within your community that are more available and easy to access.

- Provide a safe environment for your children to play. Expose your children to

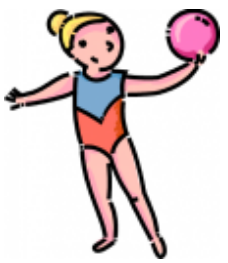
places and activities that you feel are safe and teach your children rules that promote safe boundaries. Play with friends or together as a family to help them learn those rules.

- Restrict television viewing and other screen use according the AAP guidelines. Monitor viewing, budget TV time, and choose what you allow your young children to watch. Be mindful and aware so that you can clearly communicate with your child about their screen usage.

- Do not allow your children to eat while watching television, but also eat meals together as a family with the TV off. Children often eat more and choose less healthy foods while watching TV.

Disconnecting food from TV increases awareness of food consumption, increases family communication, and decreases total TV time.

- Keep televisions and computers out of bedrooms. Children who have a television in their room watch much more television than those who do not. Their television time also tends to be unsupervised, which may create safety concerns as they get older.

- Avoid the influence of commercials - either mute the TV or use a DVR or TiVo and fast- forward through commercials. Videos/DVDs are an option with no commercials! This will limit the amount of commercials featuring unhealthy foods.

- Be a role model of healthy living and media consumption. Eat healthfully, be active, and limit how much media you use. Your child will more likely do the same now and for the rest of his or her life.

\section{Internet Resources}

The following are reliable resources for parents and professionals interested in how they can take control of the issue of media and its impact on young children's health.

\section{American Academy of Pediatrics Media Matters: \\ www.aap.org/advocacy/mediamatters.htm:}

Provides an overview of AAP's campaign about media and its effects on children as well as advocacy and policy statements, public education brochures, and PowerPoint presentations on media issues.

www.aap.org/obesity: Also check the AAP's overweight and obesity site for recommended books and brochures for parents on growing up healthy.

Centers for Disease Control and Prevention: www.cdc.gov/nccdphp/dnpa/obesity/childhood/in dex.htm: The CDC offers facts and tips for parents and professionals on childhood overweight and obesity concerns.

Center on Media and Child Health: www.cmch.tv: Created by Children's Hospital Boston, Harvard Medical School and Harvard School of Public Health, provides fact sheets for parents, teachers, and researchers.

\section{Center for Screen-Time Awareness:}

www.screentime.org: Sponsors campaigns, such as the Turn Off TV Week, to bring awareness to families regarding their media use.

\section{Children Now:}

www.childrennow.org/issues/media: A national 
organization that evaluates and advocates for public policy concerning children's issues, including the impact of media on children's health.

\section{CommonSense Media}

(www.commonsensemedia.org): Provides resources and reviews of movies, TV shows, games, music, books, and Web sites (includes ages 2-4 and 5-7, as well as older).

\section{Healthy Habits for Healthy Kids}

(www.wellpoint.com/healthy parenting/index.htm l): A nutrition and activity guide for parents.

\section{National Institute on Media and the Family} (www.mediafamily.org/facts/facts_tvandobchild.s html): NIMF sponsors the MediaWise movement. This site provides fact sheets and tips, video game report cards, Internet safety, and activities and quizzes related to media.

\section{Nutrition Explorations}

(www.nutritionexplorations.org): Information for parents and educators, plus fun online nutrition games for kids.

\section{The Center for Weight and Health}

(www.cnr.berkeley.edu/cwh/index.html): Offers programs, projects, and materials focused on childhood obesity.

\section{We Can!}

(www.nhlbi.nih.gov/health/public/heart/obesity/w ecan): The National Institutes of Health and the Department of Health and Human Services, sponsor the We Can! Program (Ways to Enhance Children's Activity and Nutrition). The focus of the program is on three main objectives: improve food choices, increase physical activity, and reduce screen time. Although it targets families with children ages 8-13, it's never too early to start adapting some of the healthy behaviors promoted through this program. Great resource for parents and professionals.

\section{Endnotes}

\footnotetext{
${ }^{1}$ Institute of Medicine of the National Academies (2004). Overview of the IOM's childhood obesity prevention study. (Fact Sheet). Washington, DC: Author.

${ }^{2}$ Mendoza, J.A., Zimmerman, F.J., Christakis, D.A. (2007). Television viewing, computer use, obesity, and adiposity in US preschool children. International Journal of Behavioral Nutrition and Physical Activity 4(44). Retrieved September 3, 2008, from http://www.ijbnpa.org/content/4/1/44.

${ }^{3}$ Dehghan, M., Akhtar-Danesh, N., Merchant, A.T. (2005). Childhood obesity, prevalence and prevention. Nutrition Journal 4(24). Retrieved September 3, 2008, from http://www.nutritionj.com/content/4/1/24.

${ }^{4}$ Jordan, A. (2007). Heavy television viewing and childhood obesity. Journal of Children and Media 1(1),
} 46-54.

${ }^{5}$ Lempert, T. (2005, April 27). Childhood obesity fueled by marketing tactics [Letter to the editor of San Francisco Chronicle]. Retrieved from http://www.childrennow.org/newsroom/press_coverage/c hildhood_obesity_op_ed.html.

${ }^{6}$ Kaiser Family Foundation (2004). Kaiser Family

Foundation releases new report on role of media in childhood obesity: Washington panel discussion to explore role of media/policy options. Retrieved October 30, 2008, from

http://www.kff.org/entmedia/entmedia022404nr.cfm?Ren derforPrint $=1$.

${ }^{7}$ Roberts, D.F. \& Foehr, U.G. (2008). Trends in media use. The Future of Children 18(1),11-37. Retrieved September 3, 2008, from http://www.futureofchildren.org/pubsinfo_show.htm?doc id=674322.

${ }^{8}$ See Endnote \#2.

${ }^{9}$ Hersey, J.C., \& Jordan, A. (2007, March). Reducing children's TV time to reduce the risk of childhood overweight: The children's media use study. U.S. Department of Health and Human Services, Centers for Disease Control and Prevention. Retrieved October 30, 2008, from http://www.cdc.gov/nccdphp/dnpa/publications/index.htm

${ }^{10}$ See Endnote \#2.

${ }^{11}$ Laurson, K.R., Eisenmann, J.C., Welk, G.J., Wickel, E.E., Gentile, D.A., \& Walsh, D.A. (2008). Combined influence of physical activity and screen time recommendations on childhood overweight. The Journal of Pediatrics, 153, 209-214.

12 See Endnote \#2.

${ }^{13}$ (1) Ekelund, U., Brage, S., Froberg, K., Harro, M., Anderssen, S.A. et al. (2006). TV viewing and physical activity are independently associated with metabolic risk in children: The European youth heart study. PLoS Med 
3(12). (2) Utter, J., Neumark-Sztainer, D., Jeffery, R., \& Story, M. (2003). Couch potatoes or French fries: Are sedentary behaviors associated with body mass index, physical activity, and dietary behaviors among adolescents? Journal of the American Dietetic Association, 103(10), 1298-1305.

${ }^{14}$ Ritchie, L.D., Welk, G., Styne, D., Gerstein, D.E. \& Crawford, P.B. (2005). Family environment and pediatric overweight: What is a parent to do? Supplement to the Journal of the American Dietetic Association, 105(5), S70-S79. Also see Endnote \#11.

15 See Endnote \#14.

${ }^{16}$ Vandewater, E.A., Bickham, D.S., Lee, J.H. (2006). Time well spent? Relating television use to children's free-time activities. Pediatrics 117(2), e181-e191. Retrieved October 31, 2008, from http://www.pediatrics.org/cgi/doi/10.1542/peds.2005$\underline{0812 .}$.

${ }^{17}$ See Endnote \#13.

18 See Endnote \#6.

${ }^{19}$ Batada, A., Seitz, M.D., Wootan, M.G., \& Story, M. (2008). Nine out of 10 food advertisements shown during Saturday morning children's television programming are for foods high in fat, sodium, or added sugars, or low in nutrients. Journal of the American Dietetic Association, 108(4), 673-678.

20 See Endnote \#13.

${ }^{21}$ See Endnote \#9 and Endnote \#14.

${ }^{22}$ Kunkel, D., Wilcox, B.L., Cantor, J., Palmer, E., Linn, S. (2004). Report of the APA task force on advertising and children. Section: Psychological issues in the increasing commercialization of childhood. Retrieved October 30, 2008, from

http://www.apa.org/releases/childrenads.html.

${ }^{23}$ Fitzpatrick, E., Edmunds, L.S., \& Dennison, B.A. (2007). Positive effects of family dinner are undone by television viewing. Journal of the American Dietetic Association, 107(7), 666-671. Quote is on p. 670.

${ }^{24}$ See Endnote \#14.

${ }^{25}$ See Endnote \#13.

${ }^{26}$ Francis, L.A., \& Birch, L.L. (2006). Does eating during television viewing affect preschool children's intake? Journal of the American Dietetic Association, 106(4), 598-600.

27 These recommendations are drawn from the following sources: (1) Dehghan, M., Akhtar-Danesh, N., Merchant, A.T. (2005) (Endnote \#3 above); (2)

www.cmch.tv/mentors_parents/overweight_suggestions.a sp; (3) Jordan, A., Robinson, T.N. (2008). Children, television viewing, and weight status: Summary and recommendations from an expert panel meeting. The ANNALS of American Academy of Political and Social Science.; and (4) U.S. Department of Health and Human Services, Office of the Surgeon General (2007). The Surgeon General's call to action to prevent and decrease overweight and obesity: Overweight in children and adolescents. 